\title{
NURSES MEET TO GAIN INSIGHTS INTO FIELD
}

The $2^{\text {nd }}$ Annual Nurse Study Day which recently took place included talks on the different causes and treatments for facial pain, insights into the wide range of restorative treatments available and what can be achieved in general practice and specialist/ hospital practice.

The day was completed by Dr Ken Wilson, Senior Community Dentist, whose lecture on introduction to the management of violence and aggression included practical demonstrations, role play and advice on how to diffuse potentially violent situations.

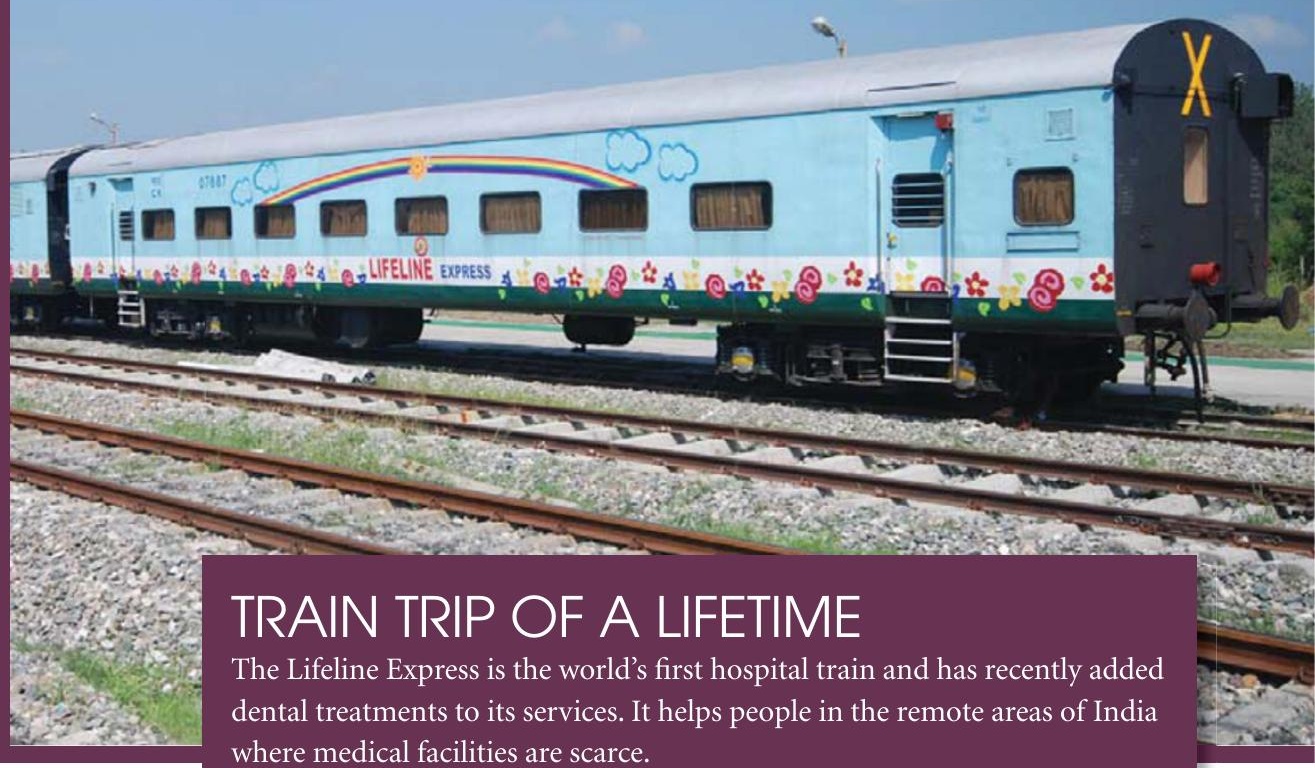

where medical facilities are scarce.

City-based dentist Neil Sikka of Barbican Dental Care plans to travel to India to provide treatment and has teamed up with Impact India Foundation to provide essential equipment for the charity's Lifeline Express on its inaugural trip.

FIRST UK ORTHODONTIC THERAPISTS GRADUATE

The first students to become qualified orthodontic therapists have recently graduated from the University Hospitals Bristol NHS Foundation Trust's Bristol Dental Hospital.

Six students from the Trust piloted the year long programme back in October 2007. The course involves a four week intensive taught programme led by consultant orthodontists combined with a placement treating patients studying under a registered specialist orthodontist trainer.

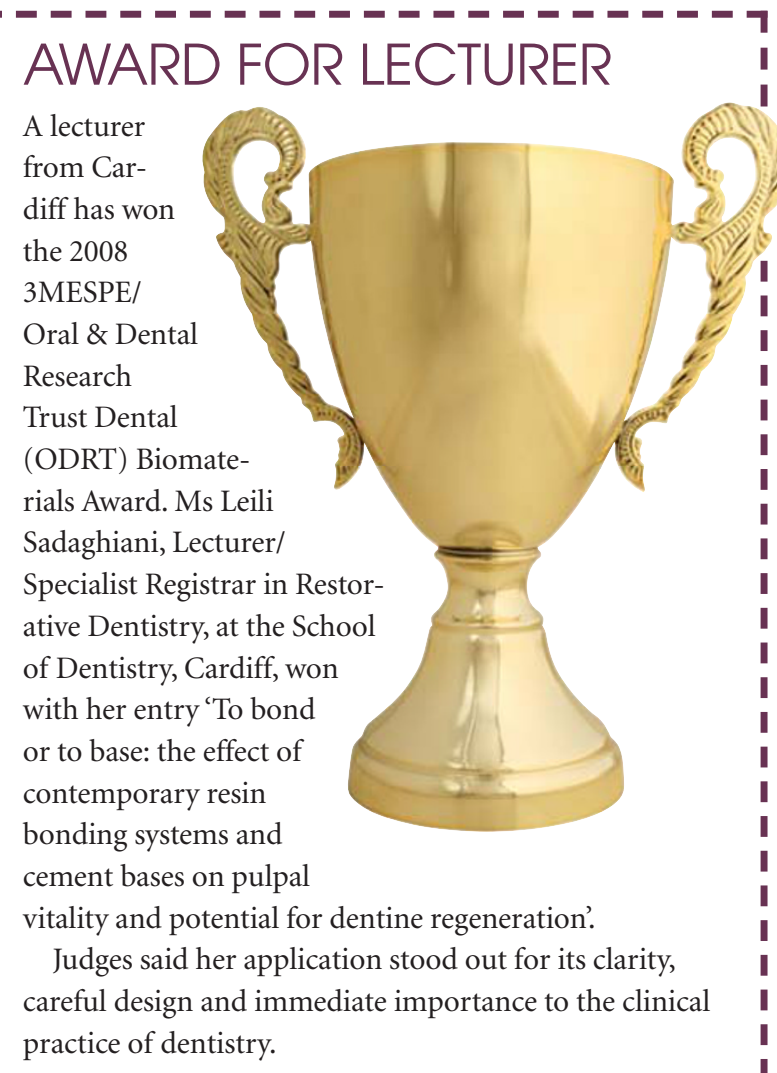

Anyone who would like to be involved in future trips should contact him at n.sikka@blueyonder.co.uk. For further information on Impact India, visit www.impactindia.org. 